Original Research Article

\title{
Evaluation of antidepressant activity of l-methylfolate per se and its interaction with escitalopram in mice
}

\author{
Sapna A. More, Pooja S. Mishra*, Ashutosh Tiwari, Savita Vyas
}

Department of Pharmacology, M.G.M. Medical College, Indore, Madhya Pradesh, India

Received: 18 June 2018 Accepted: 26 July 2018

*Correspondence to: Dr. Pooja S. Mishra, Email: drpoojasolanki@ gmail.com

Copyright: () the author(s), publisher and licensee Medip Academy. This is an openaccess article distributed under the terms of the Creative Commons Attribution NonCommercial License, which permits unrestricted noncommercial use, distribution, and reproduction in any medium, provided the original work is properly cited.

\begin{abstract}
Background: Depression is a worldwide illness in the current population. Low levels of L-methylfolate are linked to depression. Present study evaluates the antidepressive activity of acute and chronic administration of L-methylfolate per se in forced swimming test (FST) and tail suspension test (TST) and its interaction with escitalopram in albino mice.

Methods: For this 30 swiss albino mice were divided randomly into five groups $(\mathrm{n}=6)$ as group I (control,10ml/Kg, p.o) - $2 \%$ suspension of gum acacia, group II - escitalopram suspension (10mg/kg, p.o), group III- L-methylfolate suspension $(3 \mathrm{mg} / \mathrm{kg}$, p.o), group IV- L-methylfolate $(3 \mathrm{mg} / \mathrm{kg}, \mathrm{p} . \mathrm{o})$ plus escitalopram $(5 \mathrm{mg} / \mathrm{kg}, \quad$ p.o), group $\mathrm{V}$ - L-methylfolate $(3 \mathrm{mg} / \mathrm{kg}, \quad$ p.o) plus escitalopram $(10 \mathrm{mg} / \mathrm{kg}, \mathrm{p.o})$, for forced swimming test. In tail suspension test again, mice were divided in five groups as above except that the dose of Lmethylfolate was reduced to $1.25 \mathrm{mg} / \mathrm{kg}$. The pharmacologically validated models forced swimming test and tail suspension test were performed in mice to evaluate acute and chronic antidepressant activity of L-methylfolate and its combination with escitalopram respectively, after performing an acute toxicity study.

Results: L-methylfolate and L-methylfolate plus escitalopram $(10 \mathrm{mg} / \mathrm{Kg}$ and $5 \mathrm{mg} / \mathrm{Kg}, \mathrm{p} . \mathrm{o})$ showed acute and chronic antidepressant activity in albino mice in FST and TST respectively. In human L-methylfolate is only active form of folic acid that readily crosses the blood brain barrier and utilized by the CNS. It regulates the bioavailability of critical cofactor $\mathrm{BH} 4$, required by enzymes synthesizing monoamines whose deficiency leads to depression.

Conclusions: Hence, this study suggests antidepresant activity of L-methylfolate per se and as adjuvant with escitalopram when initiated from initiation of antidepressant therapy. Also, L-methylfolate opens the possibility of reducing the dose of antidepressant when used as adjuvant.
\end{abstract}

Keywords: Escitalopram, Forced swimming test, L-methylfolate, Major depressive disorder, Tail suspension test

\section{INTRODUCTION}

Major depressive disorder (MDD) is an illness that can have lasting (nearly every day for at least 2 weeks) emotional and physical manifestations, such as feeling of worthlessness, helplessness, hopelessness, guilt of indecision, change in sleep habits, loss of concentration, loss of energy, loss of interest, loss of pleasure, agitation, mental and motor slowing, drug or alcohol abuse and social withdrawal and solitariness. ${ }^{1}$

As per Age-standardised disability-adjusted life year (DALY) rates per 100,000 inhabitants India is ranked $5^{\text {th }}$ world wide for major depression, US being on number one. Depression is estimated to affect nearly 340 million people worldwide and is projected to be the second leading cause of disability in the world by the year $2020 .^{2}$ Population 
studies have consistently shown major depression to be about twice as common in women as in men, affecting 7 $12 \%$ of men and $20-25 \%$ of women. ${ }^{3,4}$ Studies suggest that $3-5 \%$ of children and adolescents suffer from clinical depression, and $10-15 \%$ have some depressive symptoms. ${ }^{5,6}$ About $1-5 \%$ of elderly people suffer from depression. ${ }^{7}$ People are most likely to suffer their first depressive episode between the ages of 30 and 40 years, and there is a second, smaller peak of incidence between ages 50 and 60 years. ${ }^{8}$

The causes of depression are not fully known. Depression is most likely due to a combination of genetic, biologic, and environmental factors. Studies have found that close relatives of patients with depression are 2 to 6 times more likely to develop the condition than individuals without a family history. Biologic Factor, the basic biologic causes of depression is strongly linked to abnormalities in the delivery of certain key neurotransmitters in the brain. The most important neurotransmitter in depression is serotonin. Imbalances in the brain's serotonin levels can trigger depression and other mood disorders. Other neurotransmitters involved in depression include dopamine, norepinephrine, epinephrine and acetylcholine. In women, the female hormones estrogen and progesterone may play a role in depression. Environmental Factors, including drugs can affect brain chemicals and trigger depression. These medications include certain types of drugs used for acne, high blood pressure, contraception, Parkinson's disease, inflammation, gastrointestinal relief and other conditions.

While MDD is sometimes viewed as one of the most "treatable" conditions, it tends to be recurrent. ${ }^{9}$ Conventional pharmacological treatment begins with monotherapy of antidepressant, but this approach is often ineffective in achieving an adequate clinical response. Regardless of the standard antidepressant medication used to start treatment, initial monotherapy compounds have comparable limitations in their overall efficacy. ${ }^{9}$ The Sequenced Treatment Alternatives to Relieve Depression (STAR*D) study concluded that full remission and also maintenance of remission was less than $30 \%$ with initial monotherapy. There was an augmentation of results when lithium, nortryptyline, MAO inhibitors were added to initial monotherapy by 16,20 and $14 \%$ respectively. ${ }^{10-12}$

Depression has been considered one of the most "treatable" of all illnesses, with authors commonly citing study response rates of $50 \%$ to $70 \%$. However, "response" has traditionally meant a reduction in score (usually 50\%) on a Hamilton Rating Scale for Depression (HDRS) or a Montgomery-Åsberg Depression Rating Scale (MADRS). A reduction in score may reflect improvement in symptoms but not full remission. In a long-term study following MDD patients, $76 \%$ of subjects who did not attain full remission (HDRS >7) had relapsed by month 15 , while a HDRS of $\leq 7$ was associated with a far lower likelihood of relapse $(25 \%)$, by month $15 .{ }^{13}$ Thus, if recovery is only partial, patients remain at high risk for a relapse, possibly as severe as their initial episode.Patients who experience full remission of MDD early in the course of treatment are more likely to remain well compared to those who showed only symptomatic improvement. ${ }^{14}$ So, the goal of therapy should be achieving and maintaining remission, rather than a reduction in severity of symptom. When no response is reported after an adequate time (generally accepted to be at least 4 weeks), and side effects are minimal, increasing the dose is a common strategy. However, if no response is reported but side effects are significant, switching agents would be preferred over dose escalation because most side effects are dose-dependent. For partial and non-responders, augmentation of antidepressants may have several advantages over dose escalation or switching. It eliminates the need to taper some medications that pose a risk of withdrawal, and augmentation may allow the patient to build on the partial response already achieved rather than risk losing that response, which can occur when switching the primary agent to a newer choice. Further, some augmentation agents can often ameliorate the side effects of primary agents (such as sexual side effects) or have other benefits (e.g., lower anxiety or help with insomnia).

Several factors, including poor long-term adherence to pharmacological therapies, have contributed to low remission rates of MDD. Discontinuation of antidepressant medication due to adverse events, the most common being sexual dysfunction and weight gain is associated with poor outcomes. Some patients prematurely terminate initial monotherapy due to perceived lack of efficacy before having had a chance to experience the potential benefits of further therapeutic steps, including the use of combination or adjunctive therapies with better safety and tolerability. ${ }^{9}$ There is an urgent need for innovative pharmacological approaches to treat MDD that increase the chance of early and complete remission. Few controlled clinical trials have been conducted to evaluate combination or adjunctive therapies implemented at the start of treatment. Administering combination or adjunctive agents at the initiation of treatment in lieu of sequenced treatment trials represents a major paradigm shift in the treatment of MDD. ${ }^{13}$ Combination therapies may work synergistically to regulate the availability of monoamines and result in a broader spectrum of action, enhancing antidepressant efficacy and long-term results. ${ }^{14}$ Six clinical trials suggest that combinations from the initiation of drug therapy may lead to more rapid clinical outcomes, higher remission rates, and lower relapse rates when compared with sequentially administered single antidepressants. ${ }^{15,16}$ Evidences from open and blinded studies has demonstrated the efficacy of L-methylfolate per se and in combination with antidepressants at initiation of therapy in reducing depressive symptoms, improving cognitive function, and reducing somatic symptoms in depressed patients with normal and low folate levels. ${ }^{17-19}$ L-methylfolate, the bioavailable form of folate, is required in the central nervous system (CNS) to aid in the synthesis of monoamines, such as serotonin, norepinephrine, and dopamine. ${ }^{20}$ Suboptimal serum and red blood cell (RBC) 
folate levels have been associated with more severe symptoms of depression, poorer response to antidepressant drugs, longer duration of illness, later onset of clinical improvement, and greater treatment resistance. ${ }^{21,22}$ Individuals with low RBC folate are six times more likely to be nonresponders to antidepressant therapy and less likely to achieve and maintain remission compared to those with normal concentrations. ${ }^{23}$ Patients known to be at risk for suboptimal CNS folate status and monoamine deficiency include older individuals, individuals with a history of poor nutrition (chronic dieting, anorexia, bulimia), individuals with a history of tobacco use or excess alcohol intake, women of childbearing age, and individuals who take medications that interfere with folate metabolism (lamotrigine, valproate, oral contraceptives, metformin, methotrexate, warfarin, fenofibrates, certain retinoids). ${ }^{24,25}$ Depressive episodes are also linked with the common inborn error of metabolism "methyltetrahydrofolate reductase polymorphism (MTHFR C677T)" associated with reduced Lmethylfolate. ${ }^{26,27}$ There is growing recognition that the combination of L-methylfolate plus an antidepressant from initiation of treatment may result in greater efficacy and more rapid improvement in depressive symptoms compared to standard antidepressant monotherapy. ${ }^{9,28}$

\section{METHODS}

The study was done at Mammalian and Experimental Pharmacology Lab, Department of Pharmacology, M.Y Hospitals and M.G.M Medical College, Indore. Forced swimming test and tail suspension test were performed in mice to evaluate acute and chronic antidepressant activity of L-methylfolate and its combination with escitalopram respectively, after performing an acute toxicity study. The procedures in this study were performed in accordance with the CPCSEA Guidelines for the Care and Use of Laboratory Animals. The protocol of the study was approved by the Animal Ethics Committee of the Institution and all efforts were made to minimize animal suffering and to reduce the number of animals used in the experiments.

\section{Acute toxicity study}

As per OECD, 2006 guidelines acute toxicity study was done in female mice. ${ }^{29}$ The animals were observed for any gross behavioral changes, sedation, morbidity and mortality. Based on preliminary studies doses of 1.25 and $2.5 \mathrm{mg} / \mathrm{kg}$ (ten times of human dose) were selected for further experiments.

\section{Animals}

Adult Swiss albino mice weighing 18-25gms, 30 for each experimental model of depression were taken. Swiss albino mice were weighted and marked at different sites for identification. They were separated into five groups of six mice each with equal number of male and non pregnant female mice. Mice were maintained at constant room temperature $\left(22-25^{\circ} \mathrm{C}\right)$ with free access to water and food, under a 12:12 h light/dark cycle (lights on at 05:00 pm) in cages, separated by sex. Animals (male and female mice were homogeneously distributed among groups) were acclimatized to the laboratory for at least $1 \mathrm{~h}$ before testing and were used only once throughout the experiments. All manipulations were conducted in the light phase, between 09:00 am and 04:00 pm.

\section{Forced Swimming Test ${ }^{30}$}

A group of 30 mice was divided at random into five groups $(n=6)$ and treated as group I (control) - $2 \%$ solution of gum acacia suspension in a dose of $10 \mathrm{ml} / \mathrm{Kg}$, group II escitalopram suspension in dose of $10 \mathrm{mg} / \mathrm{kg}$, group III- Lmethylfolate suspension in dose of $3 \mathrm{mg} / \mathrm{kg}$, group IV- Lmethylfolate in dose of $3 \mathrm{mg} / \mathrm{kg}$ plus escitalopram in dose of $5 \mathrm{mg} / \mathrm{kg}$, group V- L-methylfolate in a dose of $3 \mathrm{mg} / \mathrm{kg}$ plus escitalopram in a dose of $10 \mathrm{mg} / \mathrm{kg}$. All the drugs were administered orally 1 hour prior to the FST. Mice were placed in the acrylic cylinder for $15 \mathrm{~min}$ (pre- test session) 24 hours before the test session. After the pre-test session mice were again exposed to the same conditions for $15 \mathrm{~min}$ (test session). Basal readings (pre-test readings) were taken then drugs were administered and again the test session repeated to record post treatment effects. The mouse was judged immobile if it remained floating in the water, except for small movements to keep its head above the water.

\section{Tail suspension test $(\text { TST })^{31}$}

A group of 30 mice were divided at random into five groups $(n=6)$ and with the help of feeding syringe were treated as group I - gum acacia suspension $2 \%$ in a dose of $10 \mathrm{ml} / \mathrm{Kg}$, group II - escitalopram suspension in dose of $10 \mathrm{mg} / \mathrm{kg}$, group III - L-methylfolate suspension in dose of $1.25 \mathrm{mg} / \mathrm{kg}$, group IV - L-methylfolate in dose of $1.25 \mathrm{mg} / \mathrm{kg}$ plus escitalopram in dose of $5 \mathrm{mg} / \mathrm{kg}$, group V - L-methylfolate in a dose of $1.25 \mathrm{mg} / \mathrm{kg}$ plus escitalopram in a dose of $10 \mathrm{mg} / \mathrm{kg}$. All drugs were administered orally. The solutions were administered once daily between 1-3 pm over a period of 21 days. Mice were suspended (pre test session) for $5 \mathrm{~min}$ on a wire tied between two stands by an adhesive tape placed one $\mathrm{cm}$ from the tip of the tail individually 24 hours before the test session. Twenty four hours after the pre test session the mice were again exposed to the same conditions for 5 min (test session). Between the pre-test session and main session drug solutions were administered orally three times as follows: just after the pre test session, $5 \mathrm{~h}$ before the main test and $1 \mathrm{~h}$ before the main test. The mice are suspended individually on a metal wire tied between two stands. This wire lies $50 \mathrm{~cm}$ above the table top. The duration of immobility is recorded for a period of 5 minute. Mice are considered immobile when they hang passively and completely motionless for $60 \mathrm{sec}$ at a stretch. The test was performed between 1-3 p.m. Test was performed on the $7^{\text {th }}$, $14^{\text {th }}$ and $21^{\text {st }}$ day during the course of study after recording basal values on day 0 . 


\section{RESULTS}

Escitalopram $(10 \mathrm{mg} / \mathrm{Kg})$ did not reduce immobility period during evaluation of acute antidepressant activity in FST. Whereas L-methylfolate $(3 \mathrm{mg} / \mathrm{Kg})$ per se, L-methylfolate plus escitalopram $(3 \mathrm{mg} / \mathrm{Kg}+10 \mathrm{mg} / \mathrm{Kg})$ and $\mathrm{L}-$ methylfolate plus escitalopram $(3 \mathrm{mg} / \mathrm{Kg}+5 \mathrm{mg} / \mathrm{Kg})$ demonstrated reduced immobility period in mice in FST model when analysed by paired t-test (dependent) (Table 1). From this it was concluded that escitalopram did not show any acute antidepressant activity. Whereas Lmethylfolate, L-methylfolate plus escitalopram $(10 \mathrm{mg} / \mathrm{Kg})$ and L-methylfolate plus escitalopram $(5 \mathrm{mg} / \mathrm{Kg})$ showed acute antidepressant activity in mice and can be seen in Table 1.

Table 1: The influence of L-Methylfolate and its combination with escitalopram on immobility time in forced swimming test.

\begin{tabular}{|llll|}
\hline Group & $\begin{array}{l}\text { Dose } \\
(\mathbf{m g} / \mathrm{Kg}) \text { orally }\end{array}$ & \multicolumn{2}{l|}{ Pmmobility period for 15 min (sec) } \\
\hline Control & $10 \mathrm{ml} / \mathrm{Kg}$ & $729.00 \pm 2.47$ & Post treatment \\
\hline Escitalopram & 10 & $729.83 \pm 2.79$ & $727.83 \pm 2.27$ \\
\hline L-methylfolate & 3 & $731.17 \pm 2.104$ & $720.00 \pm 3.45$ \\
\hline L-methylfolate + Escitalopram & $3+5$ & $731.83 \pm 2.04$ & $648.00 \pm 3.89^{\mathrm{a}}$ \\
\hline L-methylfolate + Escitalopram & $3+10$ & $729.33 \pm 2.90$ & $652.33 \pm 4.65^{\mathrm{a}}$ \\
\hline
\end{tabular}

Paired t-test (Dependent)

Values are Mean \pm SEM, $n=6, \mathrm{df}=5$

ap $<0.001$ compared to pretreatment immobility period

The column represents the mean duration of immobility recorded in a 15 min observation period

When results of forced swimming test were analysed by one way analysis of variance [ANOVA] followed by bonferronis multiple comparison test it was found that Lmethylfolate showed antidepressant activity per se. Its antidepressant activity is greater in its combination with 10 and $5 \mathrm{mg} / \mathrm{Kg}$ of escitlopram as compared to escitalopram alone (Table 2).

L-methylfolate $(1.25 \mathrm{mg} / \mathrm{kg})$ also reduced the immobility period though less than escitalopram and in its combination with 10 and $5 \mathrm{mg} / \mathrm{Kg}$ of escitalopram in mice in TST model used for evaluation of chronic antidepressant activity. Results were analysed by one way analysis of variance (ANOVA) followed by bonferronis multiple comparison test,that is L-methylfolate showed chronic antidepressant activity per se, but less than escitalopram. Its antidepressant activity is greater in its combination with 10 and $5 \mathrm{mg} / \mathrm{Kg}$ of escitlopram as compared to escitalopram alone (Table 3 ).
Table 2: The influence of L-Methylfolate and its combination with escitalopram on immobility time in FST.

\begin{tabular}{|lll|}
\hline Group & $\begin{array}{l}\text { Dose } \\
\text { (mg/kg) } \\
\text { orally }\end{array}$ & $\begin{array}{l}\text { Immobility period } \\
\text { for 15 min (sec) }\end{array}$ \\
\hline Control & $10 \mathrm{ml} / \mathrm{kg}$ & $727.83 \pm 2.27$ \\
\hline Escitalopram & 10 & $720.00 \pm 3.45$ \\
\hline LMF & 2.5 & $648.00 \pm 3.89^{\mathrm{a}, \mathrm{b}}$ \\
\hline LMF+Escitalopram & $2.5+5$ & $652.33 \pm 4.65^{\mathrm{a}, \mathrm{b}}$ \\
\hline LMF+Escitalopram & $2.5+10$ & $643.33 \pm 5.51^{\mathrm{a}, \mathrm{b}}$ \\
\hline
\end{tabular}

One way F 1344; ANOVA P <0.001

One way ANOVA followed by Post hoc bonferonni comparison test Values are Mean \pm SEM, $n=6, d f=4,25$

a $\mathrm{p}<0.001$ as compared to control; $\mathrm{b} \mathrm{p}<0.001$ as compared to Escitalopram

The column represents the mean duration of immobility recorded in a 5 min observation period

Table 3: The influence of L-Methylfolate and its combination with escitalopram, on immobility time in TST.

\begin{tabular}{|llllll|}
\hline \multirow{2}{*}{ Groups } & Dose & Pre Treat. & \multicolumn{3}{l|}{ Immobility period for 5 min (sec) } \\
& mg/kg & & $\mathbf{7 ~ d a y s}$ & $\mathbf{1 4}$ days & 21 days \\
\hline Control & 10 & $207.50 \pm 2.34$ & $209.17 \pm 0.91$ & $210.67 \pm 1.40$ & $210.50 \pm 1.80$ \\
\hline Escitalopram & 10 & $209.00 \pm 1.52^{\mathrm{a}}$ & $132.83 \pm 2.05^{\mathrm{a}}$ & $129.67 \pm 3.07^{\mathrm{a}}$ & $128.33 \pm 2.81^{\mathrm{a}}$ \\
\hline L-methylfolate & 1.25 & $209.83 \pm 2.16^{\mathrm{a}}$ & $184.17 \pm 1.49^{\mathrm{a}}$ & $181.00 \pm 0.57^{\mathrm{a}}$ & $182.00 \pm 1.39^{\mathrm{a}}$ \\
\hline L-methylfolate + Escitalopram & $1.25+5$ & $210.83 \pm 1.77$, $^{\mathrm{ab}}$ & $100.50 \pm 5.03^{\mathrm{a}, \mathrm{b}}$ & $100.33 \pm 3.60^{\mathrm{a}, \mathrm{b}}$ & $104.17 \pm 4.68^{\mathrm{a}, \mathrm{b}}$ \\
\hline L-methylfolate + Escitalopram & $1.25+10$ & $210.50 \pm 8.21^{\mathrm{a}, \mathrm{b}, \mathrm{c}}$ & $76.00 \pm 4.76^{\mathrm{a}, \mathrm{b}, \mathrm{c}}$ & $74.67 \pm 4.30^{\mathrm{a}, \mathrm{b}, \mathrm{c}}$ & $76.83 \pm 4.28^{\mathrm{a}, \mathrm{b}, \mathrm{c}}$ \\
\hline
\end{tabular}

One way F 0.331281364 284; ANOVA p >0.005<0.001<0.001<0.001; One Way ANOVA followed by Post hoc Bonferonni multiple comparison test

Values are Mean \pm SEM, $n=6$, df 4, 25; a $\mathrm{p}<0.001$ as compared to control; b $\mathrm{p}<0.001$ as compared to Escitalopram; $\mathrm{c} p<0.001$ as compared to Lmethylfolate + Escitalopram $(1.25+5)$; The column represents the mean duration of immobility recorded in a 5 min observation period 


\section{DISCUSSION}

Considering the lack of preclinical studies dealing with the antidepressant-like activity of L-methylfolate, this study therefore sought to investigate the effect of this vitamin in the forced swimming test (FST) and the tail suspension test (TST) in mice.

Folic acid (folate) is a water-soluble B-vitamin whose biologically active form is L-methylfolate, which participates in the transfer of 1-carbon units (such as methyl, methylene, and formyl groups) to the essential substrates involved in the synthesis of DNA, RNA, and proteins.

Ingested folic acid can be converted to its physiological forms. This process is initiated by dihydrofolate reductase in a two-step reaction; the first step, conversion to dihydrofolate (DHF) is a slow and rate-limiting step. In the second, more rapid, step dihydrofolate is further reduced to THF. THF is then converted into L-methylfolate, the form that is normally found in the circulation and in tissues. L-methylfolate is also replenished by the conversion of folinic acid (5 formyltetrahydrofolate), an active metabolite of folic acid. Because de novo folate synthesis is not present in the CNS, it depends on adequate folate transport across the blood-brain barrier. Lmethylfolate is the only bioactive form of folate that can cross BBB. ${ }^{32}$ Within neurons; part of the folate pool will be catabolized by oxidation to dihydrofolates and folic acid, which can be reconverted to THF by dihydrofolate reductase.

Preclinical studies have shown that systemic and central administration of folic acid produces antidepressant-like effect in two predictive models of antidepressant activity, the forced swimming test (FST) and tail suspension test (TST). ${ }^{33}$

In this study we performed the forced swimming test (FST) and tail suspension test using the active form of folic acid that is L-methylfolate. Acute effects of L-methylfolate were evaluated by the forced swimming test (FST) model and its chronic effects were demonstrated by tail suspension test model of depression in which mice were treated for 21 days with the test and standard drugs and evaluation was done on days 7, 14 and 21 .

For statistical analysis, Comparisons between experimental and control groups were performed by Paired t-test and One-Way ANOVA followed by bonferroni comparison test when appropriate $\mathrm{P}<0.05$ was considered significant.

Acute study using forced swim test when analysed through paired t-test, $\mathrm{df}=5, \mathrm{p}<0.001)$ demonstrated that Lmethylfolate, and the combination of L-methylfolate plus escitalopram in both the doses $10 \mathrm{mg} / \mathrm{Kg}$ and $5 \mathrm{mg} / \mathrm{Kg}$ showed significant antidepressant activity. Escitalopram did not show any acute antidepressant activity.
In acute study using forced swim test when analysed through one-way analysis of variance (ANOVA, $\mathrm{F}_{4,25}=$ 1344, P <0.001), L-Methylfolate demonstrated significant reduction in immobility period compared to control and escitalopram monotherapy $(\mathrm{p}<0.001)$. Its combination with 5 and $10 \mathrm{mg} / \mathrm{kg}$ of escitalopram also reduced immobility period significantly compared to control and escitalopram alone. L-Methylfolate combination with escitalopram did not show significant difference in immobility period when compared to L-Methylfolate alone.

In chronic study using tail suspension test, $\operatorname{ANOVA}\left(\mathrm{F}_{4,25}=\right.$ $281,364,284, \mathrm{P}<0.001$ ), it was found that escitalopram $(10 \mathrm{mg} / \mathrm{Kg})$ shortens the total duration of immobility; Lmethylfolate also shortens the total duration of immobility which showed that LMF itself got antidepressant like properties, but less than escitalopram. L-methylfolate plus escitalopram $(10 \mathrm{mg} / \mathrm{Kg})$ shortens the total duration of immobility more than escitalopram alone.

L-methylfolate with half dose of escitalopram $(5 \mathrm{mg} / \mathrm{Kg})$ also shortens the total duration of immobility more than escitalopram alone at days 7, 14 and 21. These observations support the antidepressant effects of Lmethylfolate alone and in combination with antidepressant escitalopram when administered at the start of treatment, as total duration of immobility resembles the pattern of depression seen in human beings. L-methylfolate also showed the possibility of reducing the dose of antidepressant when used as adjuvant, which will help to reduce the adverse effects related to the use of antidepressants.

Depression is well known to involve dysregulation of one or more monoamines serotonin (5-HT), norepinephrine (NE), and dopamine (DA). L-methylfolate acts as an important regulator of a critical cofactor $\mathrm{BH}_{4}$ needed for neurotransmitter synthesis. ${ }^{34}$ L-methyloflate combines with $\mathrm{BH}_{2}$ to synthesize $\mathrm{BH}_{4}$ utilizing methyltetrahydrofolate reductase enzyme. $\mathrm{BH}_{4}$ is a necessary cofactor for the rate-limiting enzyme hydroxylase for serotonin, dopamine and norepinephrine synthesis.

Another mechanism of antidepressant activity of Lmethylfolate is its role in the homocysteine cycle. ${ }^{35}$ High CNS homocysteine levels are associated with depression, dementia, and stroke, as well as negative symptoms of schizophrenia. Homocysteine is transformed to methionine utilizing $\mathrm{B}_{12}$ and L-methylfolate, both necessary cofactors for this transformation. Methionine is then converted to s-adenyl-methionine, which serves as the methyl donor for all three monoamines-serotonin, norepinephrine, and dopamine. Thus, patients with low CNS L-methylfolate are less able to convert homocysteine to methionine, the first necessary step of the homocysteine cycle. 


\section{CONCLUSION}

L-methylfolate demonstrated antidepressant properties per se. Combination of L-methylfolate with escitalopram $(10 \mathrm{mg} / \mathrm{Kg})$ demonstrated a significantly improved antidepressant activity compared with escitalospram alone. The combination also showed an improved antidepressant activity when the dose of escitalopram was decreased to half $(5 \mathrm{mg} / \mathrm{Kg})$. L-methylfolate thus opens the possibility of reducing the dose of antidepressant escitalopram when used as adjuvant, which will help to reduce the adverse effects related to the use of antidepressants. It can be concluded that, initiating antidepressant therapy along with L-methylfolate is more effective for treating depression.

\section{ACKNOWLEDGEMENTS}

The authors are grateful to acknowledge Dr. R.P. Agrawal, Ex-Professor and Head, Department of Pharmacology, M.G.M. Medical College, Indore, (M.P.) for his guidance and support in carrying out the work.

Funding: No funding sources

Conflict of interest: None declared

Ethical approval: The study was approved by the Institutional Animal Ethics Committee

\section{REFERENCES}

1. American Psychiatric Association. Diagnostic and statistics manual of mental disorders: DSM-I, $4^{\text {th }} \mathrm{Ed}$; Washington D.C.,2000.

2. Paulden M, Palmer S, Hewitt C, Gilbody S. Screening for postnatal depression in primary care: cost effectiveness analysis. BMJ. 2009 Dec 23;339:b5203.

3. Depression Guideline Panel. Clinical Practice Guideline Number 5: Depression in Primary Care Volume 1: Detection and Diagnosis. Rockville, Md: HHS; AHCR publication; 1993:93-0550.

4. Diagnostic and Statistical Manual of Mental Disorders. $4^{\text {th }}$ Ed. Washington, DC: American Psychiatric Association; 1994.

5. Cheung AH, Zuckerbrot RA, Jensen PS, GLAD-PC Steering Group, et al. Guidelines for Adolescent Depression in Primary Care (GLAD-PC) II. Treatment and Ongoing Management, Pediatrics. 2007;120(5):1313-26.

6. Clark MS, Jansen KL, Cloy JA. Treatment of Childhood and Adolescent Depression. AFP. 2012;86(5):442-8.

7. Nelson JC, Delucchi KL, Schneider LS. Moderators of outcome in late-life depression, a patient-level metaanalysis. Am J Psychiatry. 2013;170(6):651-9.

8. Eaton WW, Anthony JC, Gallo J. Natural history of diagnostic interview schedule/DSM-IV major depression. The Baltimore Epidemiologic Catchment Area follow-up. Arch Gen Psychiat. 1997;54(11):9939.
9. American Psychiatric Association. Practice guideline for the treatment of patients with major depressive disorder (revision). Am J Psychiatry. 2000;157(4):145.

10. Trivedi MH, Rush AJ, Wisniewski SR, Nierenberg AA, Warden D, Ritz L, et al. Evaluation of outcomes with citalopram for depression using measurementbased care in STAR* D: implications for clinical practice. American journal of Psychiatry. 2006 Jan $1 ; 163(1): 28-40$.

11. Gaynes BN, Davis L, Rush AJ, Trivedi M, Fava M, Wisniewski SR. The aims and design of the Sequenced Treatment Alternatives to Relieve Depression (STAR* D) study. Primary Psychiatry. 2005 Feb;12(2):36-41.

12. Paykel ES, Ramana R, Cooper Z, Hayhurst H, Kerr J, Barocka A. Residual symptoms after partial remission: an important outcome in depression. Psychological medicine. 1995 Nov;25(6):1171-80.

13. Ginsberg LD, Oubre AY, DaouD YA. L-methylfolate plus SSRI or SNRI from treatment initiation compared to SSRI or SNRI monotherapy in a major depressive episode. Innovations in clinical neuroscience. 2011 Jan $1 ; 8(1): 19$.

14. Nelson JC, Mazure CM, Jatlow PI, Bowers Jr MB, Price LH. Combining norepinephrine and serotonin reuptake inhibition mechanisms for treatment of depression: a double-blind, randomized study. Biological psychiatry. 2004 Feb 1;55(3):296-300.

15. Fava M, McCall WV, Krystal A, Wessel T, Rubens R, Caron J, et al. Eszopiclone co-administered with fluoxetine in patients with insomnia coexisting with major depressive disorder. Biological Psychiatry. 2006 Jun 1;59(11):1052-60.

16. Keller MB. The long-term treatment of depression. J Clin Psychiatry. 1999;60(17):41-5.

17. Di Palma C, Urani R, Giorgetti V, Dalla Verde G. Is methylfolate effective in relieving major depression in chronic alcoholics? A hypothesis of treatment. Current therapeutic research. 1994 May 1;55(5):559-68.

18. Passen M, Cucinotta D, Abate G, Senin U, Ventura A, Badiale MS, et al. Oral 5'-methyltetrahydrofolic acid in senile organic mental disorders with depression: results of a double-blind multicenter study. Aging Clinical and Experimental Research. 1993 Feb 1;5(1):63-71.

19. Stahl SM. Novel therapeutics for depression: Lmethylfolate as a trimonoamine modulator and antidepressant-augmenting agent. CNS Spectr 2007;12(10):739-44.

20. Wesson VA, Levirr AJ, Joffe RT. Change in folate status with antidepressant treatment. Psychiatry Resrearch. 1994; 53(3):313-22.

21. Coppen A, Bolander-Gouaille C. Treatment of depression: time to consider folic acid and vitamin B12. J Psychopharmacol. 2005;19(1):59-65.

22. Papakostas GI, Iosifescu DV, Renshaw PF, Lyoo IK, Lee HK, Alpert JE, et al. Brain MRI white matter hyperintensities and one-carbon cycle metabolism in non-geriatric outpatients with major depressive 
disorder (Part II). Psychiatry Research: Neuroimaging. 2005 Dec 30;140(3):301-7.

23. Serot JM, Christmann D, Dubost T, Bene MC, Faure GC. CSF-folate levels are decreased in late-onset AD patients. J Neural Transm. 2001;108(1):93-9.

24. Chanson A, Cardinault N, Rock E, Martin JF, Souteyrand P, D'Incan M, et al. Decreased plasma folate concentration in young and elderly healthy subjects after a short-term supplementation with isotretinoin. J Eur Aca of Dermatol and Venereol. 2008 Jan;22(1):94-100.

25. Kelly CB, Mcdonnell AP, Johnston TG, Mulholland C, Cooper SJ, Mcmaster D, et al. The MTHFR C677T polymorphism is associated with depressive episodes in patients from Northern Ireland. J Psychopharmacol. 2004 Dec;18(4):567-71.

26. Gilbody S, Lewis S, Lightfoot T. Methylenetetrahydrofolate reductase (MTHFR) genetic polymorphisms and psychiatric disorders: A HuGE review. Am J Epidemiol. 2007;165(1):1-13.

27. Godfrey PS, Toone BK, Bottiglien T, Laundy M, Reynolds EH, Carney MW, Flynn TG, Chanarin I. Enhancement of recovery from psychiatric illness by methylfolate. The Lancet. 1990 Aug 18;336(8712):392-5.

28. L-Methylfolate. (Monograph) Alternative Medicine Review. 2006;11(4):330-7.

29. OECD. OECD Guidelines for Testing of Chemicals [internet]. France: OECD Publishing; 2006. Section 4, Health effects: Test No. 425: Acute oral toxicity: Up and down procedure.
30. Detke MJ, Johnson J, lucki I. Acute and chronic antidepressant drug treatment in the rat forced swimming test model of depression. Exp Clin Psychopharmacol. 1997;5(2):107-12.

31. Steru L, Chermat R, Thierry B, Simon P. The tail suspension test: a new method for screening antidepressants in mice. Psychopharmacology. 1985 Mar 1;85(3):367-70.

32. Farah A. The role of L-Methylfolate in depressive disorder. CNS Spectrums. 2009;14(1):suppl 2:1-8.

33. Brocardo PS, Budni J, Kaster MP, Santos ARS, Rodrigues ALS. Folic acid administration produces an antidepressant-like effect in mice: evidence for the involvement of the serotonergic and noradrenergic systems. Neuropharmacol. 2008;54:464-73.

34. Stahl SM. Novel therapies for depression: 1methylfolate as a trimonoamine modulator and antidepressant agent. CNS Spectr. 2007;12:739-44.

35. Bjelland I, Tell GS, Vollset SE, Refsum H, Ueland PM. Folate, vitamin B12, homocysteine, and the MTHFR $677 \mathrm{C} \rightarrow \mathrm{T}$ polymorphism in anxiety and depression: the Hordaland Homocysteine Study. Archives of general psychiatry. 2003 Jun 1;60(6):61826.

Cite this article as: More SA, Mishra PS, Tiwari A, Vyas S. Evaluation of antidepressant activity of 1methylfolate per se and its interaction with escitalopram in mice. Int J Basic Clin Pharmacol 2018;7:1721-7. 